\title{
Hacia una nueva percepción del espacio urbano: la ciudad como extrañamiento y como nostalgia
}

\author{
María Teresa Zubiaurre-Wagner \\ Universidad Nacional Autónoma de México \\ Instituto Tecnológico Autónomo de México
}

U no de los temas espaciales más recurrentes de la novela es la geografía urbana. Ésta no sólo se representa en oposición al ámbito rural! sino como entidad autónoma dispuesta a reconstruir en el texto la peculiar idiosincrasia de la metrópolis moderna y postmoderna. Nacen así las novelas cuyo protagonista es la ciudad, a lo Manhattan Transfer y Berlín Alexanderplatz, y se consagra con ellas el nuevo subgénero novelesco del «Grossstadtroman.» Pero este tipo de narrativa no es el único que importa: al fin y al cabo, el paisaje urbano es componente narrativo esencial de innumerables textos, y en todos ellos la ciudad, sin necesidad de ser la protagonista, adquiere indudable valor semántico:

The city always speaks, and with many voices. It has been a powerful image in literature since literature began: Whenever writers have chosen to use it, they have evoked and orchestrated responses with many overtones for both themselves and their readers. (Pike 1981,9)

Las ciudades significan, sí, pero lo hacen siempre dentro de una arraigada tradición histórico-cultural que crea y alimenta sus propios tópicos o «clichés,» y que sólo lentamente los abandona y sustituye por otros. Burton Pike (1I) hace referencia a «esa otra dimensión de la narratividad urbana,» cuando señala la necesidad de ajustarse a la retórica convencional a la hora de emprender el diseño literario de la metrópolis. ${ }^{2}$ Puede dentro del presente contexto estable- 
cerse un paralelismo entre convención retórica y cliché temático: el segundo obliga tanto como la primera, y la innovación de los mecanismos retóricos no exige menos parsimonia que la sustitución de los viejos «temas» urbanos por otros nuevos. A pesar de la relativa «resistencia» a los cambios (que son, sobre todo, de percepción de la realidad) éstos finalmente se imponen y poco a poco la ciudad de la literatura va escribiendo su historia y enriqueciendo su colección de estereotipos espaciales.

Nos interesan los clichés por dos razones fundamentales: en primer lugar, porque marcan con notable exactitud la evolución de la sensibilidad ante el fenómeno urbano; $y$, en segundo lugar, porque los temas espaciales-heredados de la novela decimonónica y la narrativa modema---eonstituyen la materia prima con que la ficción contemporánea construye sus ciudades. Ella, claro está, los moldea a su manera, les rinde pleitesía, en un acto de confirmación y celebración del estereotipo, o hace en cambio de los patrones heredados parodia y burla metafictiva.

Las combinaciones y estrategias narrativas del cliché espacial son muchas, y no se trata de enumerarlas gratuitamente sino de reconocerlas en las novelas que se comentarán en el presente estudio y de señalar su función narrativa. Interesa igualmente dar fe de la dirección en que avanza el diseño del espacio urbano en la narrativa, y registrar el surgimiento, uso y alteración de los tópicos, así como el (re)nacimiento, evolución y arraigo de otros modelos nuevos de percepción espacial-la metáfora, por ejemplo, de la ciudad como texto-n el seno de la narrativa contemporánea.

Toda recapitulación histórica habrá de partir necesariamente de la novela realista, puesto que constituye, en verdad, el género que consagra el espacio urbano en literatura y, por tanto, la creadora también de los clichés más añejos y arraigados. Digamos en primera instancia que, sobre todo en el ámbito alemán y anglosajón (véase nota 1), la reacción ante la ciudad es de un profundo pesimismo, el cual se manifiesta en un obstinado rechazo de lo que se entiende por modo de vida artificial y desnaturalizado. La consecuencia inevitable es un renacimiento vigoroso de la idealización del campo y de la existencia aldeana, y esta idealización nostálgica se materializa en el peculiar modo, en la novela realista, de diseñar el espacio de la gran ciudad. Se trata precisamente de «reconciliar» al lector con un paisaje nuevo, y para ello hay que buscar las gradaciones sutiles, y el acercamiento moroso (a través de imágenes familiares capaces de restituir la confianza) a 10 que sin esas medidas precautorias desconcertaría excesivamente al público.

La urbe decimonónica comienza siendo espacio «inserto»y polémico, el cual se define por comparación y contraste con la naturaleza (Fisher 1988, 106). Más adelante, sin embargo, la ciudad se convertirá definitivamente en totalidad «autónoma,» en universo separado y autosuficiente que no necesita, para 
establecer su identidad, oponerse a otros espacios, o complementarse con ellos. Para Perels (1983), por ejemplo, los límites de la ciudad coinciden con las fronteras del mundo.

Là autonomía espacial, pues, es el primer paso hacia la moderna representación de la gran ciudad. Sin embargo, el espacio urbano del siglo XIX seguirá aún así ostentando rasgos conservadores, al constituirse en entorno abarcable, y sin las propiedades de desmesura y laberíntica desorientación que, a partir del Simbolismo y el Expresionismo, caracterizan a la novela moderna. La urbe decimonónica se representa, en la narrativa de su siglo, como una organizada colección o «cadena» (<<Bilderkette,» según Hauser 1988) de espacios e imágenes acotados, lo cual ha llevado a Isernhagen (1983) a hablar de una visión «caleidoscópica» de la realidad, frente a esa otra visión «laberíntica» propia de la ficción moderna.

A pesar de que la transición del caleidoscopio al laberinto no es sólo posible sino incluso inevitable en la historia de la narrativa occidental lo cierto es que la novela realista sólo se vuelve «laberíntica» en episodios aislados, a los que sigue siempre un restablecimiento del orden: la «iconografía de la desorientación,» como lo llama Isernhagen, y que define con precisión el diseño espacial de muchas novelas modernas y contemporáneas, evoluciona siempre hacia una «iconografía de la reorientación» en la ficción decimonónica.

En su afán, pues, de plasmar en sus páginas ciudades «inofensivas,» de orientación segura y dispuestas siempre a someterse a la voluntad (a la mirada) de sus habitantes, recurre la novela realista a una serie de temas o «estrategias» espaciales. La vista panorámica y el jardín ${ }^{3}$ constituyen, ciertamente, los dos modos de captación y de expresión del espacio urbano más apropiados para dar a éste un «aire» de «inofensiva»y tranquilizadora naturaleza. En el primer caso, el campo sirve de oportuno engarce a la ciudad; en el segundo, la naturaleza, convenientemente «domesticada,» se apodera de un rincón de la metrópolis; pero además, ambos espacios contribuyen a «reducir» la realidad urbana: el panorama enmarca y acota la ciudad, el jardín es réplica y miniatura, es mise en abîme de un espacio más amplio: basta recordar los jardines. en Prinzessin Fisch de Raabe y La Conquéte de Plassans de Zola, reflejo, en pequeño, de las intrigas citadinas.

Pero el jardín y la visión panorámica no son las únicas estrategias espaciales, no son los únicos sistemas de reducción con que la novela decimonónica pretende organizar y hacer abarcable el espacio urbano. La miniatura (o la «miniaturización»), el espacio enmarcado, el mise en abime abundan en la narrativa que nos ocupa, y se materializan en distintos objetos, hacen uso de diferentes símbolos espaciales. Brüggemann (1985, 13) justifica la fascinación con la linterna mágica, invento del siglo XIX, con esa otra fascinación que durante esa misma época suscitatodo lo reducido, toda réplica, en pequeño, de 
una realidad que, contemplada en su verdadera dimensión, resultaría confusa, y escaparía a los sentidos. Ante el caótico espectáculo urbano, la miniatura se hace necesidad. «The city--eorrobora Wohl-is innaccesible to the imagination unless it can be reduced and simplified» (524).

Las propiedades, pues, que Brüggemann (13) observa en la linterna mágica (ésta enmarca y acota un espacio, se concentra en un punto y, por tanto, selecciona y hace posible una contemplación distanciada de la realidad), junto con esa otra marcada tendencia de no renunciar a los espacios naturales, pueden atribuirse a otros objetos, y a otros espacios, empleados con la misma finalidad en la narrativa decimonónica.

El objeto más cercano, sin duda, a la linterna mágica es el catalejo, artefacto empleado con profusión y parecida intencionalidad en la novela decimonónica: «Instrumentos como el catalejo o el telescopio permiten contemplar un detalle aislado, desglosarlo del conjunto, enfocarlo y, por tanto, ensayar una organización de la mirada» (Hauser 1988, 120). El catalejo del Magistral, en La Regenta de Clarín cumple, entre otras, con las funciones que le atribuye Hauser. La novela decimonónica hace, pues, uso frecuente de ese instrumento (tanto en su versión real o imaginaria) así como de su capacidad de acercar y «ampliar» un espacio y una realidad distantes. Pero el catalejo tiene una segunda virtud: como observa el estudioso, éste se halla capacitado para encuadrar objetivos «móviles,» lo cual obliga al propio marco a moverse con la imagen.

Al marco móvil del catalejo se le opone ese otro marco inmóvil, mucho más frecuente, mucho más empleado en la narrativa realista, de la ventana como uno de los mecanismos más eficaces para «acotar» la realidad. El fragmento espacial (ya sea interior, o exterior) encuadrado por ésta llega a tener, en ciertas novelas, aspiraciones de totalidad. Antes, pues, que de reducción, habría que hablar de «ampliación» del espacio:

Comprendí--confiesa el protagonista de Die Chronik der Sperlingsgasse sentado frente a la ventana-que el universo entero puede concentrarse en un punto. Yeso es lo que ocurre precisamente con este libro de estampas y de sueños que es la calle del gorrión. El escenario es pequeño, los que en él aparecen son pocos y, sin embargo, bien pueden encerrar todo un mundo de interés. $^{4}$

Hay ciertos «marcos fijos,» ciertos modos de acotación y reducción espaciales que se destacan por su acento «nostálgico,» y adverso a la experiencia de la ciudad, y que se suman a los ya estudiados de la vista panorámica y el jardín. Así, no es infrecuente, sobre todo entre las novelas del llamado «Realismo poético» alemán, situar la trama en los márgenes de las grandes metrópolis, en aquellos barrios de las afueras que se destacan, todavía «incontaminados,» ante el horizonte urbano. Desde ellos, la ciudad puede todavía contemplarse con un distanciamiento físico y espiritual. Otras veces, el argumento 
tiene lugar exclusivamente en aquellos distritos-más campestres que urbanos, con sus parques, jardines y amplias avenidas bordeadas de árboles, en donde se aloja la aristocracia y la alta burguesía (Perels 1983, 60-62). Finalmente, como ocurre en Die Chronik der Sperlingsgasse, y aún desarrollándose la narración «dentro» de la ciudad, en su mismo centro, no ofrece sino el retrato restringido de una sola área metropolitana,S con la excepción de un largo paseo por el campo. La acción novelesca, pues, se concentra casi exclusivamente en el reducido ámbito de un solo barrio-en realidad, de una sola calle, situada en un barrio popular de Berlín--eon ánimo. de hacerle sentir al lector que lo que en él acontece y le es narrado, resume la vida entera, y reproduce, en miniatura, el universo. De la ciudad propiamente dicha, pues, sólo se nos muestra lo que, desde la perspectiva contemporánea, tiene de menos urbano: una barriada con talante de pueblo, en donde todos se conocen y cuyos límites perfectamente definidos casi nunca se traspasan. Para reforzar la impresión de aldea, por fin, se contrarresta la imagen del barrio con esa otra imagen de la excursión campestre, y entremedias, nada, como si para llegar al campo no hubiera necesariamente que atravesar la ciudad. ${ }^{6}$

Importa notar que la acotación de los espacios es, en la novela realista, un proceso en potencia «infinito,» por cuanto admite y aún aplaude la presencia de sucesivas reducciones. Recordemos que en La de Bringas, novela de Galdós, el domicilio de don Víctor, sito en uno de los pisos superiores del Palacio Real, edificio que refleja en dimensiones reducidas las intrigas del país, es a su vez taller en donde el artista amateur se afana en una segunda reproducción en miniatura de la realidad, utilizando como materia prima las finísimas hebras del cabello humano.

La ventana, ese objeto, como ya apuntamos, limitador y enmarcador por excelencia de larealidad, y por ello mismo empleado con profusión en la ficción decimonónica, sirve, en Irrungen Wirrungen, como punto de apoyo para la instalación estratégica de otro artilugio reductor. La protagonista de la novela de Fontane se entretiene en mirar a través de un ingenioso espejo giratorio, el cual arrastra hasta el interior lo que está fuera (lo «domestica,» pues) y convierte el tráfago urbano en pequeño e inocente cuadro decorativo.

Fuera, junto a la ventana, había instalado un espejo giratorio ... La señora Pittelkow se sentó frente al espejo, no por vanidad o presunción (ya que ni siquiera se veía en él) sino por pura curiosidad y ganas de entretenerse "' Stine ... le tapó los ojos con la mano y dijo:-Ya basta, Pauline. Como si no conocieras de sobra la calle de los Inválidos.

-Tienes razón, hija. Pero así es el ser humano: se divierte con las cosas más tontas. Y cuando me pongo a mirar por el espejo y veo los caballos, y a toda esa gente, me parece que no es lo mismo que verlos así, sin más. Es otra cosa, 
creo yo, porque el espejo empequeñece, y empequeñecer casi equivale a embellecer.

Hemos querido, con estos ejemplos aislados, insistir en la importancia y variedad de los mecanismos de reducción espacial en el seno de la novela realista. La lista de estos mecanismos, es claro, puede prolongarse, pero nuestra intención va más allá de su simple enumeración y.comentario. Lo fundamental ya está dicho, a saber: el narrador decimonónico gusta de ofrecer a sus lectores un universo «total,» pero muy sobre todo, abarcable y por tanto, compartimentado. Belgum $(1992,21)$ hace referencia, por ejemplo, a «the preoccupation of the nineteenth century with creating containers, cases, sheaths and 'housings' for anything and everything.» Bajo la pluma del narrador decimonónico, pues, la realidad urbana, cuando no se «tiñe» o disfraza de naturaleza, se reduce a pequeños cuadros, se condensa y refleja en miniaturas, en armónicas escenas muchas veces de índole doméstica.

Hasta aquí, la ciudad se nos aparece fundamentalmente como conjunto estático y «espacializado,» como estampa pictórica «plana,» de dimensiones siempre abarcables y función evocadora. La metrópolis decimonónica tiene todavía, lo mismo que sus habitantes y sus lectores, nostalgia y voluntad de aldea.

La transformación de lo que Pike (1981) califica de «ciudad estática» (propia de la novela realista) en «ciudad fluyente» y de fronteras huidizas (presente sobre todo en la ficción moderna) obedece a un lento proceso cuya primera muestra evidente son los poemas de Baudelaire, y más tarde, esas ciudades inquietantes y hostiles que nacen de la pluma de Joyce, Woolf, Musil, Katka, Eliot, Dos Passos, Dreiser y Doeblin. Con todos ellos, la geografía urbana se vuelve materia flexible, y se transforma, las más de las veces, en laberinto, un laberinto que metaforiza la creciente inseguridad y desasosiego del individuo ante una realidad tambaleante. El nuevo e intrincado diseño urbano no puede por tanto atribuirse ya a la memoria fotográfica de un observador imparcial, sino al estado de ánimo (el cual'actúa de prisma deformador) del personaje que la contempla.

En el Realismo se detecta todavía el resabio romántico de, en palabras de Amiel, hacer de la naturaleza espejo del alma. Pero sólo con el Fin de Siglo, esa facultad reflejante es atribuida también al paisaje urbano. Éste, por cierto, va adquiriendo matices más complejos y se perfecciona en el arte de significar metafóricamente la realidad. La ciudad deja paulatinamente de ser mero escenario urbano, esqueleto de piedra y asfalto. Se convierte, de pronto, en organismo viviente, dotado de un sistema nervioso que con frenética celeridad emite estímulos contradictorios y de difícil asimilación. No obstante, esta atropellada emisión de sensaciones no brota tanto de la urbe como entidad «física,» como conjunto arquitectónico, sino de la aglomeración humana que 
en ella se asienta. A partir del Simbolismo (aunque no deban descartarse antecedentes realistas de notable interés) el foco de atención literaria se desvía hacia la multitud urbana. Al viejo estereotipo fundamentado en la antítesis naturaleza-civilización, le sustituye, pues, un nuevo contraste, tan fructífero, desde una perspectiva artística y literaria, como sil antecesor, e igualmente abocado a convertirse en tópico: el fenómeno de la masa enfrentada a la sensibilidad individual, la cual con paradigmática frecuencia se encama en la figura solitaria del «flaneur.»

«El tráfago callejero tiene algo de repugnante, algo contra lo que reacciona siempre la naturaleza humana,» reza ya un testimonio de Engels. Vuelve, pues, el pesimismo, y se mantiene, con pocas variantes, en la narrativa alemana. La francesa, en cambio, y tal y como supo notar Klotz (1969) en su análisis de Victor Rugo, descubre en el fenómeno de la muchedumbre una serie de virtudes, entre ellas, las de afiadir movilidad al entorno urbano.

El espacio, pues, se dinamiza, la ciudad, como anticipamos, abandona su estática rigidez, y la mirada del escritor se posa cada vez con mayor interés en la aglomeración de sus habitantes. La multitud, por cierto; encierra, como fenómeno literario, su propia contradicción: porque, como apunta Freisfeld $(1982,52)$, «la representación de la muchedumbre urbana va unida, desde sus primeras manifestaciones artísticas, al concepto de soledad, encarnado en el paseante solitario.» Este «flaneur,» o paseante solitario, encama casi siempre al intelectual o al artista cuya sensibilidad se siente violentada con el espectáculo del anonimato y fiereza de la muchedumbre urbana.

A punto de empezar el siglo XXI, y en el seno de la novela contemporánea y postmoderna, la antítesis multitud urbana versus paseante solitario hace ya mucho que ha perdido su eficacia artística, aunque, como todos los tópicos literarios, todavía puede dar fruto si se le utiliza como resorte nostálgico, si se hace de ella comentario paródico o metafictivo. Y, sin embargo, sus ensefianzas perduran en los modernos experimentos narrativos: porque esa impresión de movilidad, de inabarcabilidad acentuada por la presencia de la muchedumbre--la sensación inquietante de que las fronteras urbanas y sociales fluctúan y se borran, de que la ciudad, à la postre, es laberinto-ha ingresado también en la narrativa contemporánea. La diferencia principal es que el elemento desorientador no es ya la masa (un factor externo, pues), sino la propia conciencia del que recorre la ciudad. Ésta se le ofrece, no ya como presente, sino como megamemoria que le trae, sin cesar, recuerdos del pasado, recuerdos borrosos que se mezclan con vivencias actuales y hacen imposible la organización coherente de la realidad. Sirva como ejemplo de ello el Nouveau Roman en general, pero sobre todo dos novelas paradigmáticas: Dans le Labyrinthe, de Robbe-Grillet y L'Emploi du Temps, de Butor. 
Los paisajes urbanos, en la narrativa contemporánea, tienden a despoblarse, y sugieren al lector imágenes fantasma de ciudades abandonadas, muy parecidas a las que De Chirico retrata en sus cuadros. En estos terrenos baldíos, se distorsiona la percepción y recupera el recuerdo escenas olvidadas. La memoria, aquí, es la fuerza motriz que impulsa la narración, pero además, a través de ella logra la novela introducirse en el mundo c0ntemporáneo. Porque memoria, hoy en día, inevitablemente nos hace pensar en el lenguaje informatizado, y, por extensión, en esos sistemas supranacionales de comunicación por computadora que (corno antes la ciudad) empequeñecen repentinamente el mundo y acercan, corno por arte de magia, lo que nunca se pensó pudiera estarjunto. Los motivos y ternas que en su día inspiraron la narrativa han quedado obsoletos en el caso de la novela contemporánea. El manido contraste naturaleza-civilización ha agotado buena parte de su capacidad inspiradora (ahora que ha logrado cautivar la opinión pública, y se ha hecho fuerte con los movimientos ecologistas). La mirada del novelista, por otro lado, ya no se posa en la multitud urbana, que está claro ya no impresiona sus sentidos. Nadie parece razonar innovativamente, a estas alturas, sobre otra de las tradicionales oposiciones, la que enfrenta masa e individuo, en la línea ya consagrada de un Poe o de un Rilke, ni se lamenta el poeta o el novelista melancólicamente de la «soledad en compañía,» enfermedad, verdadera epidemia urbana que ya apuntarnos se ha convertido en cliché tanto sociológico como literario. Pero, aunque es cierto que la novela contemporánea ya no puede diseñar un paisaje urbano con los mismos instrumentos-ahora convertidos en estereotipos--empleados por la narrativa anterior, no es menos verdad que la ficción postmodema es deudora, ya para siempre, de esta sutil progresión en el arte de mirar y de describir que se consagra con el Realismo y se intensifica y quintaesencia con el Nouveau Roman. La novela contemporánea ha aprendido, pues, dos cosas: que la descripción puede muy bien utilizarse corno recurso metonímico (reflejo, prolongación o condicionante del estado espiritual o/y físico del personaje), o puede disfrutar de una (aparente) autonomía, cuando adopta ese tono «objetivizante» del Nouveau Roman, pero que ya supo emplear el existencialismo y sus estribaciones (por ejemplo, los relatos de Borchert). La adopción de ese tono imparcial y frío hace del complicado mecanismo de la percepción un nuevo terna de interés literario. De hecho, los más recientes estudios críticos se centran fundamentalmente en la «percepción urbana,» y analizan el modo peculiar en que el narrador (muchas veces, a través de los personajes) «siente» la ciudad. Sentir, percibir la.ciudad no es otra cosa, para narradores, personajes y lectores que un modo de descifrar un código complejo, de tal forma que el recorrido de la geografía urbana se convierte automáticamente en un acto de lectura. La ciudad como texto es, pues, un nuevo tópico que se suma a la ya extensa 
colección de «clichés» los cuales contribuyen al diseño de la ciudad como motivo literario.

Hemos ido, hasta ahora, «saltando» de tópico en tópico, con ánimo de trazar, a fuerza de estereotipos, la trayectoria cultural de la imagen de la ciudad: a la antítesis naturaleza-civilización y a la adherencia obstinada a lo rural en todas sus manifestaciones que permea con insistencia la novela decimonónica le sigue la definitiva conciliación con la geografía urbana, pero brota, inevitable, otro motivo de inquietud, a saber, el fenómeno alarmante de la muchedumbre, observada con recelo y desdén por el flaneur-artista. La ciudad, con ella, se dinamiza, se vuelve difusa en sus límites, e incontrolable (Fin de Siglo). La ciudad se hace laberinto, aunque la muchedumbre se retire, y el recuerdo y el presente se confunden en el dédalo de sus calles y callejas (Nouveau Roman). La memoria, por fm, la megamemoria informática que gobierna los sistemas de comunicación diluye aún más las fronteras urbanas, y reduce las grandes metrópolis occidentales y orientales a meros barrios o distritos conectados entre sí (narrativa contemporánea). Hay otras maneras de llegar a esta conclusión, otras clasificaciones, aunque de talante más bien histórico o sociológico, y no tanto cultural o de simbología literaria, que apoyan nuestras deducciones:

In tenns ofthe histOl)' of cities, David Gordon speaks ofthe Commercial City-a port of siphons of the wealth of the metropolis abroad; the Industrial City-the cite of heavy production; and the Corporate City-a high tech environment where infonnation is hoarded or exchanged. This shift has also been characterized as one from marketplace to factory town to «no town.» In literature, Frederic Jameson has seen these stages as concomitant with realism, modemism and post-modemism ... And in tenns of the social relations we practice, we might see these stages as shifts from products, to money to credit, or, as Guy Debord does in Society ofSpectacle, from being to having to appearing. (Rice 1989,222)

De esta cita nos interesa sobre todo la referencia a la postmodernidad, porque en ella crece y se expande la «no town» la «no-ciudad,» la cual ha servido de inspiración literaria a los autores contemporáneos y, por ende; a' las tres novelas que vamos a comentar en estas páginas. La metrópolis postmoderna, que los urbanistas y demógrafos prefieren denominar «megalópolis,» ha sido bautizada, por los teóricps de la literatura, como «nowhere city,» una ciudad que no está, realmente, en ninguna parte, bien porque ha perdido toda idiosincrasia y es igual a sus hermanas repartidas por el mundo, o porque el verdadero espíritu urbano, como asegura Bernstein, ya no reside en la geografía de la metrópolis o en la muchedumbre que la habita, sino en los sistemas de comunicación que funcionan como inmensa red interurbana.

Sea como fuere, no es sólo la ciudad «real,» el modelo empírico sito en la realidad, el que servirá de materia inspiradora a la narrativa contemporánea. 
Porque ésta se nutre en gran medida de materia ya elaborada y procesada, como son las convenciones y los tópicos generados por aquellos textos literarios que le preceden. La intertextualidad y la metaficción, explícitas ambas en mayor o menor grado, constituyen sus primordiales instrumentos de trabajo, y de ellos se servirán para diseñar esas ciudades imaginarias que tan bien simbolizan nuestra realidad y nuestras megalópolis de ahora.

y así, Juan Goytisolo, con su novela Juan sin tierra devuelve a los tópicos urbanos su eficacia expresiva, su capacidad de significar y de decir algo nuevo y moderno. Nos hallamos con esta novela ante un hábil desplazamiento (quizá, sea mejor decir «ensanchamiento») de los estereotipos recuperados. Parece que vuelve, con la pluma de Goytisolo, el contraste naturaleza/civilización del romanticismo rousseauniano, aunque esta vez se nos presente eficazmente camuflado con lajerg a postestructuralista y postmoderna de la «filosofía de los márgenes.» La multitud urbana (la civilización) es ahora la «masa» informe (e uniforme) de occidente. La naturaleza y su bondad residen de pronto en oriente, en los aborígenes, en el «buen salvaje» del tercer mundo ignorado por occidente. Los medios de transporte superan los límites urbanos. Las grandes ciudades, unidas velozmente por aviones, se han convertido en los distintos barrios de Europa y de Norteamérica. El «fláneur» se hace turista, 8 el paseante, en la cultura occidental, lo es ahora del mundo.

En este último aspecto, a Juan Goytisolo lo secundan Miguel Espinosa, Botho Strauss y Rafael Sánchez Ferlosio: los cuatro escritores denuncian con sarcasmo el turismo vacío, la burguesía impermeable y hermética que se traslada de un lugar a otro cargando con sus pétreas convicciones; pero sólo Sánchez Ferlosio, con El testimonio de Yarfoz, va más allá de la mera condena, y al turismo estéril opone el viaje consistente y creador, con el que recupera y se adhiere a otra grantradición literaria, la del Bildungsroman. La estructura de la novela de aprendizaje le sirve, pues, como pretexto para la construcción de una de las más densas utopías de la postmodernidad, y que mejor retrata, por vía de la nostalgia y del diseño de una urbe ideal, la sociedad contemporánea y sus deficiencias.

Pero analicemos primero Juan sin tierra, que, como dijimos, es sarcástica denuncia del burgués cómodamente emplazado en su mundo. Un mundo que los avances de la técnica han hecho pequeño y uniforme, pero que. al burgués se le hace suficientemente grande, y sobre todo, extensible y «desplegable,» porque a todas partes va con él, como si lo que lo rodeara fuera siempre un gran vacío, dispuesto a dejarse llenar, y su mundo, algo portátil, y afanoso, con ferocidad ignorante, de ocupar cualquier espacio. Es su actitud, cuando viaja y traspasa fronteras, la misma que la de la burguesía acomodada del siglo XIX, la cual trasladaba al campo, en sus ratos de asueto, las mismas comodidades (y las mismas creencias) que la acompañaban en la ciudad. Por eso, aunque Juan 
sin tierra no sea una novela «urbana» propiamente dicha, sí reúne todas las condiciones del texto narrativo construido dentro de un espacio metropolitano, el cual sirve de propulsor al argumento y potencia su cargazón ideológica. Las grandes metrópolis, que el novelista hace muy poco retrataba como temibles precisamente por su dimensión inabarcable (en 1906, H. G. Wells habla en The Fuiure OiAmerica de «limitless bigness,» refiriéndose a Nueva York) se han quedado pequeñas, pero las coordenadas semánticas, el sistema de significados sigue siendo el mismo. La burguesía no crea espacios nuevos, ni absorbe otras convicciones, y si se sale de su «barrio,» es tan sólo para expandirse y ocupar lo que a ella se le antoja «vacío.»

Goytisolo, pues, no modifica el sistema semántico (ni desdeña los tópicos urbanos) sino que lo asienta, para conservar su eficacia, en un «macroespacio;» este macroespacio adquiere esa magnitud que antes sugería la metrópolis y que ahora sólo sugieren el mundo occidental, los viajes organizados y la invasión temporal de espacios «exóticos.»

Juan sin tierra completa la ya sustanciosa colección de novelas «poemáticas» que han enriquecido en los últimos años el panorama español y occidental. Nos presenta un mundo, en palabras de Sobejano $(1992,507)$, de «riqueza connotativa inagotable,» y un espacio simbólico, universal que no se ajusta necesariamente a unas coordenadas geográficas, sino que antes que un paisaje, busca retratar, en este caso particular, una moral, un modo de vida que trasciende las fronteras. Este comportamiento, no adscrito a ningún lugar en particular (por eso, «Juan sin tierra»), se repite, invariable, tanto en la húmeda abundancia vegetal de Cuba, como en el ondulante desierto de Marruecos, como en la estereotipada y gélida imagen de la lujosa estación de esquí emplazada en los alpes suizos. Nos hallamos, pues, ante un solo destinatario, la segunda persona de singular del relato, y ante la voz del narrador demiurgo que denuncia con obstinación la estupidez y vaciedad de unos dogmas (burgueses) heredados: frente a la sexualidad contenida y pacata de sus padres \{ símbolo de esa «parejita reproduCtora» del mundo occidental que se repite entre los ricos hacendados cubanos, entre los zares rusos, en la «guapaza peninsular y su marido de bigotito,» etc.) la sexualidad desenfrenada y libre de los esclavos negros, de los árabes, frente al mundo estructurado, condicionado espacial y temporalmente, de la creación novelesca, el desbordamiento incontenible de la escritura, el movimiento rítmico (y sexual) de la pluma-falo, que salta libremente de un tiempo a otro, que crea una espacialidad infinita: la espacialidad de un texto sin fronteras, de, un paisaje «comodín,» porque cualquier pedazo de tierra sirve para encamar el símbolo.

Los paisajes o espacios diseñados en la novela son dos:

1) El «espacio total» del símbolo, materializado en ese libre saltar de un espacio geográfico a otro, en esa impresión de enorme extensión sin fin, exótica 
superficie de paisajes estereotipados, de paisajes-cliché copiados, no de la realidad, sino del «arte» de la reproducción, paisajes que son como tarjetas postales (la estación de esquí suiza), que son como escenas-prototipo del cine (la plantación cubana de azúcar) que caben dentro de la estrecha perspectiva del turista de viaje organizado (el zoco marroquí). Un paisaje quieto, una sucesión de fotos manidas que el escritor baraja desordenadamente. Lo estereotipado del paisaje hace recordar otros paisajes literarios: los de la novela pastoril, los de la novela caballeresca, la repetición ad infinitum del «locus amœnus,» etcétera.

2) El «espacio total» del texto: así reza la contraportada de la novela que nos ocupa: «Vertebrado por la asunción apasionada de la heterodoxia, donde el erotismo o la sátira verbal (sexo igual a verbo) se revisten de profunda significación de un quebrantamiento de las creencias y dogmas heredados, Juan sin tierra es un texto cambiante y múltiple que lleva a cabo una indagación a la vez en la escritura y en su implicación.»

Pero más interesante es aún la siguiente cita de Sobejano, porque inscribe Juan sin tierra dentro de una tendencia generalizada, la de esa ficción contemporánea que hace del proceso de escribir uno de sus principales asuntos novelísticos:

Tema cardinal de la nueva novela parece ser la busca del sentido de la existencia en el sentido de la escritura, placenteramente ejecutada y observada como una proeza de la voluntad de ser. De ahí la abundancia de imágenes de carácter oral o escritural: cintas, rollos, retahílas, pluma, página, texto, borradores, taller, escritorio. Se quiere exhibir los problemas formales de la novela misma, respondiendo así a una ética artística tan radical como el anhelo de liberación en la espontaneidad o en el placer erótico. (1992, 507)

Al espacio total del texto--único espacio, en realidad, que se nos presenta en la novela como habitable, y todavía libre y poderoso--se le opone ese «espacio real,» mejor dicho, ese símbolo espacial omnipresente que se refiere a una verdad geográfica: la de la península ibérica. Es el espacio rechazado, la topografía detestable gobernada por el modo de vida europeo.

Hay, pues, dos miradas, dos perspectivas o modos de percepción.

La mirada-prototipo, la mirada estulta del occidental, a quien su mullida satisfacción consigo mismo y sus creencias, más culturales que propiamente religiosas, nublan la vista y no le dejan ver más allá de lo que prometen las guías turísticas y los folletos de propaganda vacacional. Por eso está tan lleno el texto del moderno paisaje estereotipado, por eso la novela entera presenta una precisa (e inmóvil) topografía simbólica y denunciadora. La geografía contemplada desde el punto de vista occidental, vista a través del espejo deformante de una cultura que sistemáticamente rechaza lo que no comprende. 
y luego, esa otra mirada que busca la belleza en donde los dogmas heredados sólo descubren fealdad: la belleza de dos cuerpos enlazados en un abrazo improductivo (no producir nada igual a la denuncia de la felicidad basada en el cónsumo salvaje) sobre las arenas igualmente estériles del desierto, la belleza de la cópula audaz de los esclavos negros, su único reducto de rebeldía, su único instrumento de expresión, su ún ico canto a la libertad. Mirada ésta que parodia (sermones, entrevistas, debates, teatro, cine) y que introduce «cuñas» de verdad, retazos poéticos en defensa de los oprimidos.

Aquí, la verticalidad y horizontalidad del paisaje la determina el cuerpo humano, cuerpos yacentes, miembros erectos, elevación o denigración del espíritu por medio del acto sexual, pluma enhiesta que acude en defensa de la «rebelión del cuerpo.»

Botho Strauss, en su novela Kongress. Die Kette der Demuetigungen se sirve igualmente de la rica tradición que le ofrece la narrativa en el arte de «reproducir» el paisaje urbano. Consciente de que maneja tópicos y clichés, el escritor alemán no necesita, para el diseño de sus ciudades, más que de ciertos objetos o escenarios aislados que, colocados de fonna estratégica y sin necesidad de minuciosas descripciones, evocan con facilidad la imagen de la urbe postindustria1: la biblioteca, la plaza, el palacio de congresos, el rascacielos de lujosas oficinas, el centro comercial acristalado. Como en el caso de Juan sin tierra, no se trata de diseñar el espacio de una ciudad concreta y con idiosincrasia propia, sino de dibujar a través de símbolos o imágenes-prototipo la clásica estructuración y composición de cualquier ciudad contemporánea.

Pero no sólo interesa reproducir su geografía, sino el modo de vida que ésta impone a sus habitantes. Conviene observar que con el surgimiento de las grandes metrópolis se instaura una nueva modalidad viajera entre la clase burguesa: la del viaje de placer o de instrucción, que impone, casi como una obligación, la visita a las ilustres capitales de Europa. Más adelante, estos viajes pierden su sello de exclusividad, y el turismo se hace accesible a las clases populares, se masifica. Strauss, al igual que Goytisolo, fija su mirada crítica en la figura del turista, al cual la narrativa contemporánea achaca los mismos defectos que en su día la literatura de fin de siglo atribuía a la muchedumbre urbana: una masa indiferenciada y anónima, que actúa como fuerza animal e invasora, y que arrastra consigo al flâneur (observador que se siente distinto, y alejado de la sensibilidad comÚn) obligándole a seguir su mismo itinerario:

Nada podía alejarle tan poco de sí mismo como el largo viaje, las grandes ciudades extranjeras, que sólo visitaba para hallarlas dignas de ser vistas. En el centro de sus excursiones no estaban las avenidas, los edificios, los parques y las columnas, en el centro estaba tán sólo el interés precario y sin desarrollar que le inspiraba todo aquello, la dolorosa y paulatina desaparición de la impresionabilidad que se iniciaba una y otra vez ante los lugares, las joyas 
artísticas, los monumentos del extranjero. Y era precisamente ese modo tan torpe de experimentar y de sentir lo que más le exasperaba, lo que mayor hartazgo le producía. Pensaba: cuando emprendo mis caminatas de reconocimiento me interno irremisiblemente en las eternas rutas turísticas, que son como senderos embrujados, y que me dejan incapacitado por completo para un modo de percepción único y especial. Esos senderos fluyen siempre con universal desdén bajo los pies del transeúnte solitario, un desdén que apenas admite resistencia alguna 0 . El viaje durará cuatro horas y media. Y, nuevamente, no se verá nada. Ante las cosas, se olvidará necesariamente lo poco que quedaba de unos conocimientos ya precarios. La inconsciencia y el embrutecimiento ante esos lugares inaccesibles, esos monumentos artísticos a donde se lleva al turista, son tan misteriosos y reconcentrados que, en realidad, tendrían que metamorfosearse inmediatamente en una extraña revelación, en una suerte de éxtasis o arrobamiento históricos. Sin embargo, nunca se llega a eso: la comunidad de los mirones, de los que se fijan a medias, de los que están informados a medias, de los que disfrutan a medias, y son sólo a medias receptivos y sensibles, la comunidad de esos visitantes ligeros, que no se entregan del todo ni son tampoco del todo olvidadizos, que saben reducir y alinear las cosas todas, a los que, para poseer una cosa, les basta hallar aunque sea un parecido mínimo con otra de su conocimiento, que están absolutamente convencidos de que el objeto singular y exquisito les pertenece a ellas, las multitudes, y que por tanto sólo puede ser comprendido de manera apropiada y única hasta entonces en la historia por las multitudes medianamente instruidas: esa comunidad se tragó su conciencia. Yeso fue todo.

Dos aspectos encierra la presente cita que interesan especialmente a nuestros propósitos: en primer lugar, el indudable parecido que guarda la tradicional muchedumbre urbana, que tan amenazadora y perjudicial aparece en la narrativa finisecular, con la amorfa riada de turistas «semicultos.» Tanto los turistas como la muchedumbre urbanaactúan como fuerza igualadora y borradora de diferencias y se apropian con mano grosera de todo lo exquisito. y en segundo lugar, está esa otra referencia a los monumentos como incapaces, de tan vistos y manoseados, de servir de fuente de inspiración, o de producir en el observador sentimientos de admiración o embeleso estético. Compárese esta visión desencantada con el protagonismo que en las novelas realistas y la narrativa simbolista de Fin de Siglo adquieren en cambio los lugares artísticos, los cuales no sólo provocan admiración por su belleza, sino que se integran, casi como si de un organismo vivo se tratase, en la vida de los personajes. Strauss, indudablemente, está mucho más cerca de Kafka que de un Galdós, o de un Miró, y mencionamos sobre todo a este último porque ninguno como él ha sabido dotar de vida propia a los grandes edificios, a las catedrales, palacios, colegios, etc. en los que se recogen las instituciones. 
Para el autor de Kongress, todo signo que refiera a la vida cotidiana y a esa existencia que se agolpa alrededor de los edificios y grandes monumentos provoca inevitablemente una sensación de extrañamiento ante la realidad
¿Por qué estoy aquí? ¿Por qué estoy expuesto a toda esa gente que de forma tan intangible y manifiesta está en su casa? De toda esa gente que no necesita quedarse boquiabierta ante sus iglesias, plazas, cafés, callejuelas y fuentes, que pueden llenar de costumbre las cosas, que pueden utilizarlas, e ignorarlas parcialmente. La existencia cotidiana que nunca llega a percibirse realmente. en el país de uno, transcurre aquí ante ti, en primer plano e intocable, como una película.

Pero aún hay un tercer elemento significativo, y en el que se engarzan estos dos aspectos comentados del encuentro traumatizante con el turismo multitudinario y los monumentos artísticos que el «flaneun>-artista (el yo narrador, en la novela que comentamos, adopta actitudes idénticas a las del paseante estereotípico) sólo sabe contemplar con dolorosa indiferencia: nos referimos al viaje como otro de los tópicos estrechamente vinculados a la experiencia urbana. Strauss, impulsado por una clara intencionalidad metafictiva, obliga a su protagonista a abandonar la lectura y a sustituirla por esa segunda vía de instrucción que tradicionalmente ha sido la «Bildungsreise:» «Decidió, pues, hacer un viaje, por la sencillez de la solución, y porque prometía ser tan entretenido como leer.»

Sin embargo, en este caso nos hallamos ante una «antinovela» de formación, ante una parodia del viaje como camino que conduce hacia la sabiduría y la experiencia. La realidad, y en concreto, la realidad urbana es, para el protagonista, un texto de lectura imposible-la novela en su totalidad es un tratado sobre el hecho de leer y la experiencia lectora--del cual se extrae muy poco disfrute. Nótese, por ejemplo, cómo la entrada en el espacio urbano no presupone esa visión armónica de la ciudad vista desde lejos, tan común en los textos realistas. El entorno se presenta en seguida como confusa estructura de calles y rutas eternamente trilladas. La ciudad, lejos de aportarle una experiencia nueva, le despoja precisamente de toda capacidad de experimentar, yen vez de abrirle nuevos horizontes, se cierra en laberínticos recorridos que no conducen a ninguna parte. Pero además, la ciudad nunca se entregará al extraño, y éste se sentirá siempre fuera de lugar y excluido inevitablemente de lo cotidiano.

A estos dos novelas afanosas de presentamos con crudeza naturalista el modo de vida occidental--encarnado y simbolizado en la urbe postmoderna, en la pavorosa frialdad de sus rascacielos y edificios públicos, en la atrofia de la sensibilidad de sus habitantes, en el incesante bombardeo de los sentidos con paisajes estereotipados, en el extrañamiento del individuo sensible ante una realidad que no comprende y que le desorienta--opone Sánchez Ferlosio El testimonio de Yarfoz, la cual, como afirma Santos Sanz VilIanueva $(1992,262)$, 
es, antes que novela histórica «crónica legendaria de configuración épica.» En ella, la crítica a la sociedad contemporánea se presenta de forma solapada y disfrazada nostálgicamente de una rememoración de tiempos mejores. Sánchez Ferlosio construye sistemáticamente su utopía con materiales que ya no se uti lizan en la edificación de nuestras ciudades, y de esa manera señala ausencias y denuncia tropelías.

Yarfoz-«oscuro hidráulico» que escribe la biografía de su «querido y admirado amigo el príncipe Nébride»-es contratado para unas obras de desecación de unos grandes pantanos; pero surge un grave inconveniente: el proyecto de desecación robará el agua a dos ciudades colocadas sobre una meseta, Uriga y Múriga, las cuales se abastecen mediante una enorme rueda de riego de prodigiosa perfección ingenieri1. Esto basta para que Nébride se declare dispuesto a interrumpir su gran proyecto de desecación. Pero antes de que se resuelva el litigio, ocurre una tragedia política, la cual obliga a Nébride a exiliarse. Los atánidas lo acogen durante dos años y más adelante decide continuar el viaje hasta el país de los iscobascos. Tras descender por una prodigiosa rampa de construcción milenaria, se instala definitivamente en las tierras de los Camino-del-mar. Allí, entra a formar parte del «Real cuerpo de los necrógrafos,» encargados de redactar el texto de las lápidas, recogiendo lo más personal, característico e individualizador de los fallecidos.

También esta novela, como Juan sin tierra y como, en su mayor parte, Kongress, gira alrededor del tópico del viaje. En este caso, sin embargo, se trata de una confirmación nostálgica de su eficacia, no de una obstinada insistencia en su esterilidad. Nébride, como en la novela de aprendizaje de cuño clásico, aprende, y es receptivo a toda nueva sensación. Pero además, la compenetración con las cosas es absoluta. Las grandes obras ingenieri les y arquitectónicas, lejos de producir hastío, provocan la admiración de los visitantes y son contempladas como testimonio fehaciente del espíritu y sabiduría de un pueblo. El amor a la cosa bien hecha, las largas y minuciosísimas descripciones de los objetos, la profunda simbología de éstos como condensación del alma del pueblo que los hizo, la renuncia al poder, el desprecio de la violencia, el canto a la espiritualidad, todo este «decálogo moral» utiliza como medio de expresión metáforas espaciales. No se hace referencia alguna a la psicología de los personajes, ni se habla directamente de sus costumbres, ni importa tampoco demasiado su presente. Se habla, en cambio, del espíritu de un pueblo que entronca con su pasado. Tanto ese pasado como el alma colectiva de un pueblo se corporeizan en los monumentos-símbolo que marcan los diferentes episodios narrativos: la rueda de regar que abastece a Uriga y a Múriga, el puente de los príncipes concordes sobre el río Barcial, el camino de los iscobascos, también llamado rampa de Susurbuz, la necrópolis de los Camino-del-mar. 
La falta de individualidad, el sometimiento a lo convencional, la estandarización de la vida lo simbolizan precisamente esos «necrolitos» que recogen textos siempre iguales, y se manifiestan igualmente en esas arquitecturas que en vez de buscar el modo de acomodarse a los accidentes geográficos, en vez de respetar las formas de la naturaleza-yen eso consiste precisamente el logro prodigioso de la rampa, que respeta la peculiar estructura de la falla-imponen su propia forma a la naturaleza, allanando y dinamitando los obstáculos.

El testimonio de Yarfoz es, sin duda, una evocación nostálgica y alegórica de unos valores perdidos en la actual sociedad urbana y un lamento constante ante los desmanes del mundo industrializado y burgués, que se simbolizan igualmente a través de metáforas espaciales: ahí están, por ejemplo, las villas lujosas y todas iguales (referencia inconfundible a las modernas urbanizaciones de lujo) que los comerciantes ricos encargan a los carpinteros isobascos, ahí están también los arcos ampulosos y arrogantes los cuales señalan el comienzo de la vía que conduce a las dos ciudades «cromba;» dice Nébride que lo que quita superficialidad y vanidad a las grandes obras monumentales, lo que las «humaniza,» es ese arrimarse a ellas de otras construcciones «utilitarias,» como en el caso de los arcos, rodeados de pequeñas y baratas edificaciones que ofrecen sus mercancías y sus servicios a los viajeros. Pero, precisamente contra esas edificaciones hay una orden de demolición.

En las tres novelas comentadas reverbera con fuerza parecida el tradicional pesimismo ante el fenómeno de la ciudad, y las tres delatan, con mayor o menor intensidad, la añoranza de un medio urbano más identificado con sus habitantes: Goytisolo amplía los horizontes de la metrópolis y hace extensivos sus defectos al mundo occidental y su burda ignorancia del «otro;» Strauss retrata la soledad del artista en medio de la gélida geografía de la urbe postmoderna, que aniquila toda posibilidad de experimentación estética y hace imposible la comunicación humana; Sánchez Ferlosio, por fin, diseña su propia utopía, cuyas virtudes nos hablan persuasivamente de los graves dolencias que padece el medio urbano. En todo caso, lo cierto es que los tópicos sobre la ciudad que fueron configurándose a lo largo de la historia de la literatura se manifiestan igualmente en la narrativa contemporánea, aunque ésta, claro está, Jos transforme y adapte a sus necesidades expresivas. Se multiplican con ello los procedimientos paródicos y metafictivos, y se enriquece y gana en complejidad el arte de reproducir literariamente la realidad contemporánea de las grandes metrópolis.

\section{Notas}

1 Remitimos al tantas veces invocado «menosprecio de corte y alabanza de aldea,» que se inicia con Virgilio y que, con una serie de «altibajos,» se prolonga hasta nuestros días. La literatura alemana y anglosajona, sobre todo, es prolífica en sus críticas al 
fenómeno urbano. (Consúltese a Benjamin, Fiedler, Freisfeld, Hassan, Hauser, Hellpach, Iserhagen, Marx, Milgram, Morrison, Perels, Simmel).

2 «A writer does not speak to us directly from his experience, but through language and through the retorical conventions of literary forms. These cultural artifacts are historically determined; a writer can express himself and be understood by his readers only by using the literary conventions, vocabulary, and imaginery available to him at his particular cultural moment. He may extend them, but displaces them only at the risk of incomprehensibility.» (Pike 1981, 11)

3 Para un estudio detallado del panorama y del jardín en la novela realista remitimos al trabajo de Zubiaurre citado en la bibliografía.

4 Las traducciones del alemán son mías.

5 Blanche Gelfant $(1954,11)$ ha propuesto un modelo clasificatorio (basado en la mencionada necesidad de reducción y simplificación narrativas de la realidad urbana) que recoge tres patrones característicos: 1) la novela «retrato,» en la que la ciudad se manifiesta a través de los esfuerzos de adaptación de un personaje; 2) la novela «sinóptica,» en la que la ciudad misma actúa de protagonista; y, por fin, 3) la novela «ecológica,» que se ajusta al mecanismo simplificador al que nos referimos: «(this type ofurban novel) focuses upon one small spatial unit such as a neighborhood or city block and explores in detail the manner of life identified in this place.» (11)

6 Toni Morrison $(1981,37)$ hace una observación interesante sobre la percepción urbana que coincide con esa tendencia, tan marcada entre los realistas alemanes, a la «ruralización» y «empueblamiento» de la metrópolis: «The affection of black writers for the city seems to be for the village within it.» (37)

7 Ellaberínto constituye, según Bachelard, uno de los más persistentes arquetipos de nuestro imaginario. En la narrativa moderna, como es sabido, resurge con especial vigor, y se convierte en la estructura convencional de sus ciudades. (Para un estudio más detallado del laberinto en la novela, desde Katka y Joyce hasta el Butor y Robbe-Grillet, remitimos al trabajo de Ronse.)

8 Para un estudio de la figura del turista en un primer sentido sociológico-cultural yen una segunda acepción «metasociológica» (<<the tourist as one of the best models available for modern-man-in-general») remitimos al trabajo de Dean MacCannel1.

\section{Obras citadas}

Belgum, Kirsten. 1991. Interior Meaning. Design in the Bourgeois Home in the Realist Novel. New York: Peter Lang.

Benjamin, Walter. 1974. Charles Baudelaire. Ein Lyriker im Zeitalter des Hochkapitalismus. Frankfurt: Suhrkamp.

Brüggemann, Heinz. 1985. «Aber schickt keinen Poeten nach London!» Grossstadt und literarische Wahrnehmung im 18. und 19. Jahrhundert. Texte und Interpretationen. Hamburg: RowohIt Verlag.

Fiedler, Leslie. 1981. «Mythicizing the city.» Literature and the Urban Experience. Essays on the City andLiterature. Ed. by Michael C. Jaye andAnn Chalmers Watts. New Brunswick: Rutgers University Press. 
Fisher, Philip. 1988. «City Matters: City Minds. Die Poetik .der Grossstadt in der modemen Literatur.» Die Unwirk/ichkeit del' Stadte. Grossstadtdarstellungen zwischen Moderne undPostmoderne. Ed. Klaus R. Scherpe. Hamburg: Rowohlt Verlag. Freisfeld, Andreas. 1982. Das Leiden an del' Stadt. Spuren del' Verstadterung in deutschen Romanen des 20. Jahrhunderts. Köln: Bohlau.

Gelfant, Blanche. 1954. The American City Novel. Oklahoma: U ofOklahoma P.

Hassan, Ihab. 1981. «Cities ofMind, Urban Words: The Dematerialization ofMetropolis in Contemporary American Fiction.»Literature and the Urban Experience. Essays on the City andLiterature. Ed. by Michael C. Jaye and Ann Chalmers Watts. New Brunswick: Rutgers University Press.

Hauser, Susanne. 1988. Wahrnehmung bis 1910. Berlin: Dietrich Reimer Verlag.

Hellpach, Willy. 1952. Mensch und Volk der Grossstadt. Stuttgart: Enke.

Isernhagen, Hartwig. 1983. «Die Bewusstseinskrise der Modeme und die Erfahrung der Stadt als Labyrinth.» Die Stadt in der Literatur. Ed. Cord Meckseper und Elisabeth Schraut. Gottingen: Vandenhoeck and Ruprecht.

Klotz, Volker. 1969. Die erzahlte Stadt. Ein Sujet als Herausforderung des Romans von Lesage bis Doblin. München: Carl Hanser Verlag.

Marx, Leo. 1981. «The Puzzle of Anti-Urbanism in Classic American Literature.» Literature and the Urban Experience. Essays on the City and Literature. Ed. by Michael C. Jaye and Ann Chalmers Watts. New Brunswick: Rutgers University Press.

Milgram, Stanley. 1970. «Das Erleben der Grossstadt. Eine psychologische Analyse.» Zeitschriftfür Sozialpsychologie, 1, 142-152.

Morrison, Toni. 1981. «City Limits, Village Values: Concepts ofthe Neighborhood in Black Fiction.» Literature and the Urban Experience. Essays on the City and Literature. Ed. by Michael C. Jaye and Ann Chalmers Watts. New Brunswick: Rutgers University Press.

Perels, Christoph. 1983. «Vom Rand der Stadt ins Dickicht der Städte. Wege der deutschen Grossstadtliteratur zwischen Liliencron und Brecht.» Die Stadt in del' Literatur. Ed. Cord Meckseper und Elisabeth Schraut. Gottingen: Vandenhoeck and Ruprecht.

Pike, Burton. 1981. The Image olthe City in Modern Literature. Princeton: Princeton University Press.

Ronse, Henri. «Le Laberynthe, espace significatif.» Cahiers Internationaux du Symbolisme. 9,10: 27-43.

Sanz Villanueva, Santos. 1992. «La novela.» Historia y crítica de la literatura española. Los nuevos nombres: 1975-1990. Barcelona: Crítica.

Sobejano, Gonzalo. 1992. «Ante la novela de los años setenta.» Historia y crítica de la literatura española. Época contemporánea: 1939-1980. Barcelona: Crítica.

Zubiaurre-Wagner, María Teresa. 1994. The Place olSpace in the Novel: From Realism to Contemporary Fiction. Columbia University, Ph. D. Thesis. 